\title{
Evaluation of air lime and clayish earth mortars for earthen wall renders
}

\author{
P. Faria, V. Silva, N. Jamú, \& I. Dias \\ Nova University of Lisbon, FCT, Dep. Civil Engineering, Caparica, Portugal \\ M.I. Gomes \\ ISEL, Polythecnic Institute of Lisbon, Dep. Civil Engineering, Lisbon, Portugal
}

\begin{abstract}
An experimental rammed earth wall was traditionally made with local earth and characterized in terms of superficial hardness, compactness, thermal conductivity and water absorption, in exterior environmental conditions. Two mortars were made with an air lime and a mixture of three washed graduated siliceous sands, with volumetric proportions of 1:2 and 1:3 (air lime:sand). A clayish earth was characterized and applied as partial substitutions of air lime on 1:2 mortars and as partial substitutions of the finest sand on 1:3 mortars. Mortars were formulated and characterized in terms of constitution and consistency and samples of mortars applied on ceramic brick were prepared. For each volumetric proportion, mortars without earth and the ones with earth that presented the best workability were applied as renders on panels on the experimental rammed earth wall; also prismatic samples were made. The mortar samples and the renders on the wall were characterized at 90 days of age. This paper presents and discusses some of the results obtained with the characterization of the rammed earth wall, the fresh mortars and its application on the bricks and on the wall. Differences between the mortars are highlighted while their compatibility with traditional rammed earth wall is verified.
\end{abstract}

\section{INTRODUCTION}

Earth mortars were used in prehistoric times for the construction of vegetal structures of huts, as can be proved by traces of those mortars that underwent fire and can yet be found at archaeological sites (Bruno et al. 2010). In more recent times, loadbearing rammed earth walls became common in vernacular architecture; they continue to be built and have been characterized by several researchers (Hall \& Djerbib 2004, Bui \& Morel 2009, Faria et al. 2012). Rammed earth walls do not have to be superficially protected but the application of a render (exterior coating made of mortar layers) and a plaster (interior coating also made of mortar layers but with requirements that are different), defined by EN 998$1: 2010$, is common and, if well defined, clearly benefits the durability of the wall (Faria-Rodrigues 2005, Gomes \& Faria 2011).

Air lime-based mortars are quite common for ancient and new earthen wall renders; earth-based mortars are very common as plasters for the same type of walls (Faria et al. 2010). In fact, air lime was traditionally added to earth-based mortars whenever it was available and affordable, particularly for renders. For decades air lime mortars and earth-based mortars have not been used in many countries and its technology was almost lost (Faria et al. 2008, Mar- galha et al. 2011). Fortunately air lime-based mortars regained interest in the last couple of decades and have been studied by several researchers (Andrejkovicová et al. 2013, Coroado et al. 2010, Fragata \& Veiga 2010, Veiga et al. 2010, Arizzi et al. 2012). Meanwhile earth mortars have only been systematically studied by few researchers (Azeredo et al. 2008, Minke 2011, Stazi 2003, Pkla et al 2003) and stabilised earth mortars with little amount of air lime have also been studied by very few researchers (Fernandes et al. 2012, Gomes et al. 2012a). In this last study, mortars were formulated and characterised with a commercial earth. The behaviour of chemically unstabilised mortars was compared to similar mortars stabilised with $5 \%, 10 \%$ and $15 \%$ of binder in order to evaluate their influence. If a higher amount of air lime is present they can be called air lime-earth blended mortars.

When a conventional mineral binder is added to earth to produce a mortar, the characteristics of the earth material drastically change, for the best, for instance in terms of water resistance, and for the worst, like in terms of hygrothermal inertia (Lima 2013) and deformability. Particularly the use of hydraulic binders contributes to tragically change its behaviour.

Air lime was traditionally the more common mineral stabilisation used in earthen vernacular architecture. 
Air lime-earth blended mortars can be applied as renders and not only as plasters; they are more sustainable and compatible with old masonries and with earthen walls when compared to air lime pure mortars, to air lime-pozzolanic blended mortars and particularly to mortars with hydraulic binders. Bearing in mind what was referred, a long experimental research is being held for the formulation, characterization and evaluation of air lime mortars, air limeearth blended mortars and earth mortars. In this paper, a little part of that research will be presented and discussed.

\section{EXPERIMENTAL WORK}

\subsection{Rammed earth experimental wall}

An experimental rammed earth wall was made in June 2012 during a workshop of Centro da Terra Association at Caparica Campus of Nova University of Lisbon, with façades facing $\mathrm{E}$ and $\mathrm{W}$. The base of the wall is directly in contact with the ground and a traditional wooden formwork was used with lateral dimensions $190 \times 55\left(\mathrm{~cm}^{2}\right)$ for a wall thickness of $50 \mathrm{~cm}$. A mixture of two local soils was used, prepared with the intended optimal amount of water and it was placed inside the formwork and compacted manually with a wooden rammer in successive thin layers. After the complete filling of the formwork, it was dismounted and installed in the upper level. Little stones were used in the joints between the blocks of the formwork; a lime mortar was disposed at the borders and corners of some of the layers that completed each block (with the dimension of the formwork). The wall was completed with three levels, with $1,65 \mathrm{~m}$ high. The top of the wall was protected by ceramic tiles.

The wall was characterised after six months and/or ten months of age, in terms of thermal conductivity, with a ISOMET 2104 equipment with a probe that penetrates $10 \mathrm{~cm}$ into the wall thickness (Fig. 1, on the left). Several measurements were made at two different days, one after recent rain and another after spring sunny days. Superficial hardness was determined with a durometer shore A from PCE and with a pendular sclerometer PROCEQ PT (Fig. 1, on the right) after spring sunny days. Ultrawave velocity was determined with a PROCEQ puncit equipment with $6 \mathrm{~cm}$ diameter transducers, by an indirect or surface transmission procedure. Water absorption under low pressure was determined by Karsten tubes (Fig. 1 , in the middle) after sunny days. The tubes were fixed with plasticine and the amount of water $a b-$ sorbed after 5 minutes of contact was registered.

Due to the inexistence of basement of the wall, capillary rise went on from the ground and could be visually seen at the bottom part of the wall, once its colour was darker there.

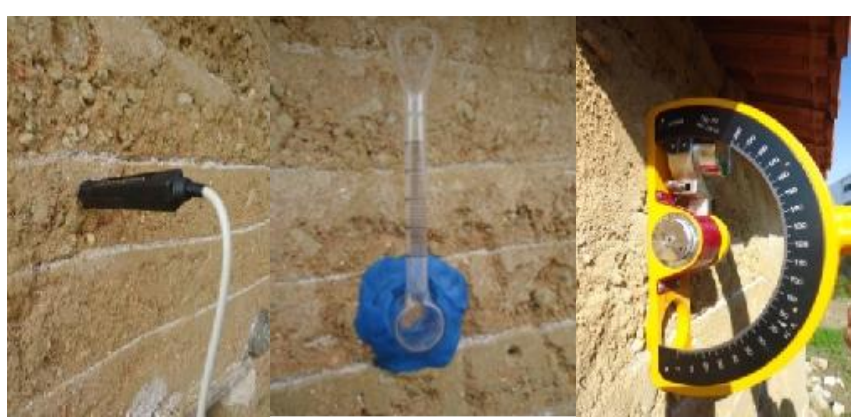

Figure 1. Rammed earth wall being tested for thermal conductivity, water absorption and hardness by sclerometer.

\subsection{Characterization of the mortar materials}

Two mortars were made with an air lime and a mixture of three washed graduated siliceous sands, with volumetric proportions of 1:2 and 1:3 (air lime:sand). A clayish earth was characterized and applied as partial substitution of air lime on 1:2 mortars and as partial substitution of the finer sand on $1: 3$ mortars.

The air lime was a hydrated power EN 459-1 CL90$\mathrm{S}$ from Lusical (CL); the clayish earth was commercialized by Sorgila and came from Redinha - Pombal. It was the same used by Gomes et al. (2012a), selected because it presented a low shrinkage when submitted to the Alcock test (Gomes et al 2012b). It was previously dried and grounded in a mill in order to break up the bigger clods. Loose bulk density of the mortar constituents is presented in Table 1, the mineralogical composition of the clayish earth is presented in Table 2 and the particle size distribution of the sands and the earth (tested by dry method and by wet method) is presented in Figure 2.

Table 1. Loose bulk density of constituents.

\begin{tabular}{lc}
\hline Loose Bulk Density & {$\left[\mathrm{g} / \mathrm{cm}^{3}\right]$} \\
\hline Calcium Air Lime (CL) & 0.362 \\
Earth & 1.084 \\
Coarser Sand (CS) & 1,412 \\
Medium Sand (MS) & 1.405 \\
Finer Sand (FS) & 1.388 \\
Mixture of Sands & 1.463 \\
\hline
\end{tabular}

Table 1 shows that, due to the low loose bulk density of air lime CL compared to the one of earth, the percentage of weight substitution of lime by earth corresponds to a lowest volume of earth. On the contrary, the percentage of weight substitution of finer sand by earth corresponds to a much higher volume of earth. It can also be noticed by Table 1 and Figure 2 that the mixture of sands corresponds to a better graduated and denser aggregate matrix than each of the sands by itself.

Figure 2 show that the clayish earth presents totally different results when its particle size distribution is tested by the wet method and by the dry method. In fact, the earth was just milled to disaggregate the bigger particles but the finer particles need water to 
completely separate from each other. The results from the dry method shows that the material is really composed by small particles and that could not be observed using the dry method.

Table 2. Mineralogical composition of clayish earth by XRD.

\begin{tabular}{ll}
\hline Compounds & Presence \\
\hline Quartz & +++ \\
Feldspates & Trc \\
Mica & Trc \\
Chlorite & $?$ \\
Kaolinite & ++ \\
Gheotite & + \\
Anatase & $+/ T r c$
\end{tabular}

+++ high proportion; ++ medium proportion; + low proportion; Trc traces; ? doubt; - not identified.

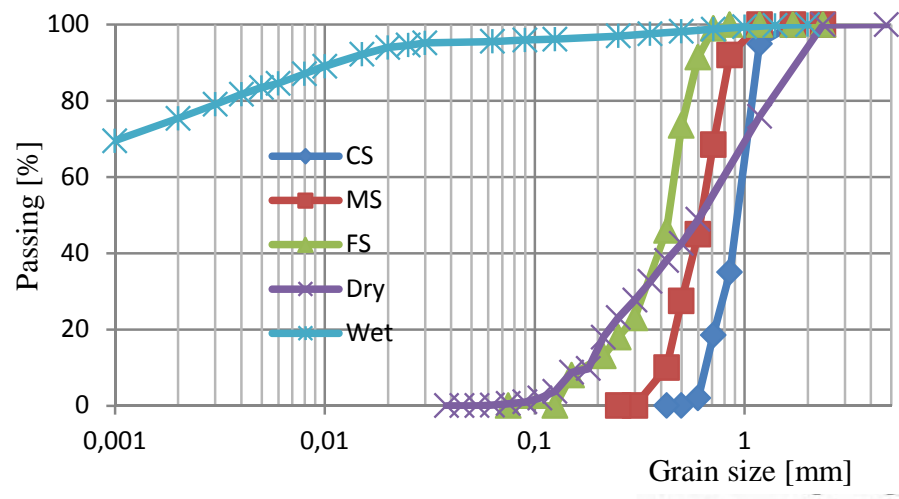

Figure 2. Particle size distribution of each sand by dry method (coarser CS, medium MS and finer FS sands) and the earth, by dry and wet methods.

\subsection{Mortars preparation and testing}

Four different proportions of clayish earth were used on 1:2 mortars substituting the same amount of lime weight - 5\%,10\%, 25\% and 50\% - and four proportions were used on 1:3 mortars, substituting the same amount of finer sand weight $-5 \%, 10 \%, 15 \%$ and $25 \%$. For the preparation of mortar the volumetric proportions were turned into weight proportions by the loose bulk density and are presented in Table 3. The dry constituents were mixed in a Controls 65L0005 mechanical laboratory mixer with the amount of water needed to achieve workability. The water was added during the first seconds of mixing and the mixing went on for 3 minutes. The water/(air lime plus earth) ratio and the flow table consistency, determined by EN 1015-3:1999, are presented in Table 3.

Mortars with volumetric proportion of 1:2, considering the binder composed by air lime or air lime+earth, correspond to a weight proportion of 1:7.7; similarly, mortars with volumetric proportion of $1: 3$, considering the aggregate composed by sand or earth+sand, correspond to a weight proportion of 1:11.6. In the first group of mortars the proportion is higher on binder but the binder is partially substitut- ed by earth, while in the second group of mortars the proportion is lower on binder but the aggregate is partially substituted by earth.

All the mortars presented a flow table consistency with an average of $151 \pm 4 \mathrm{~mm}$. Current hollowed ceramic bricks $20^{\mathrm{x}} 30\left(\mathrm{~cm}^{2}\right)$ were superficially wetted and all the mortars were applied on bricks; the mortars were left to fall from a defined height of $70 \mathrm{~cm}$, from the top of a hollowed box placed over the brick, in order to simulate always the same application energy. The box was removed and the mortar was regularized, with a thickness of $2 \mathrm{~cm}$.

All the samples of mortar over brick were let to dry at controlled conditions of $65 \pm 5 \%$ relative humidity and $20 \pm 3^{\circ} \mathrm{C}$ temperature. The samples were daily sprayed with water between the $2^{\text {nd }}$ and the $5^{\text {th }}$ day of age. No shrinkage occurred on the samples during drying and their colours varied from white to cream and very light brown.

The water absorption under low pressure of the current hollowed bricks was determinate by Karsten tubes. At the age of 90 days the mortar samples over brick were characterized in terms of thermal conductivity, using the same ISOMET equipment but with a contact probe with $6 \mathrm{~cm}$ diameter (Fig. 3), superficial hardness, ultrawave velocity and water absorption with the same equipments previously used for the characterisation of the wall.

Among the mortars with 1:2 volumetric proportion the consistency increased, for the same water/(lime+earth) ratio, when $5 \%$ and $10 \%$ of the weight of lime was substituted by earth and maintained the same value for mortars with 5\%, 25\% and $50 \%$ of earth. However an excellent workability was found for the mortar with $25 \%$ earth, better than for mortar without earth. Among the mortars with 1:3 volumetric proportion, although a decrease of water/(lime+earth) ratio was noticed, any tendency on consistency could be found but a good workability was reached particularly for the mortar with $10 \%$ earth substituting the corresponding weight of finer sand.

Table 3. Earth percentage of air lime or finer sand substitution, volumetric and weight proportions of binder (Binder:Agreggate or Calcium Lime:Earth:Sand), water/(air lime plus earth) ratio and flow table consistency of mortars.

\begin{tabular}{lrllll}
\hline Mortar & Earth & \multicolumn{2}{l}{ Vol.Pr. Wt.Pr. } & \multicolumn{2}{c}{ W/(CL+E) Consist. } \\
\cline { 2 - 5 } \cline { 5 - 6 } & [wt\%] & {$[\mathrm{B}: \mathrm{Ag}]$} & {$[\mathrm{CL}: \mathrm{E}: \mathrm{S}]$} & {$[-]$} & {$[\mathrm{mm}]$} \\
\hline CL2 & 0 & $1: 2$ & $1: 0: 7.7$ & 1.7 & 147 \\
CL2_5e & 5 & $1: 2$ & $1: 0.1: 8.1$ & 1.8 & 150 \\
CL2_10e & 10 & $1: 2$ & $1: 0.1: 8.6$ & 1.8 & 155 \\
CL2_25e & 25 & $1: 2$ & $1: 0.3: 10.3$ & 1.8 & 150 \\
CL2_50e & 50 & $1: 2$ & $1: 1: 15.5$ & 1.8 & 149 \\
CL3 & 0 & $1: 3$ & $1: 0: 11.6$ & 2.5 & 151 \\
CL3_5e & 5 & $1: 3$ & $1: 0.2: 11.4$ & 2.1 & 161 \\
CL3_10e & 10 & $1: 3$ & $1: 0.4: 11.2$ & 1.8 & 149 \\
CL3_15 & 15 & $1: 3$ & $1: 0.6: 11$ & 1.6 & 155 \\
CL3_25e & 25 & $1: 3$ & $1: 1.1: 10.5$ & 1.3 & 147 \\
\hline
\end{tabular}


Prismatic $40^{\mathrm{x}} 40^{\mathrm{x}} 160\left(\mathrm{~mm}^{3}\right)$ samples were made with the reference mortars CL2 and CL3 and mortars with the best workability among the ones with lime or finer sand substitution, CL2_25e and CL3_10e, and subjected to the same curing conditions as samples over bricks. They were demoulded at 7 days of age and used at 90 days of age for thermal conductivity determination, with the same equipment used with the samples on bricks, although the superficial thickness of the samples was only $40 \mathrm{~mm}$ and did not reach the total diameter of the probe (Fig. 3).

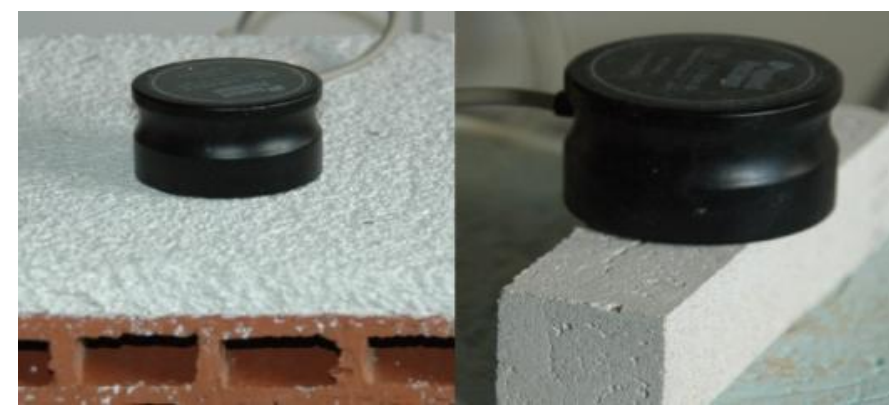

Figure 3. Mortar on brick and prismatic sample tested for thermal conductivity.

The $\mathrm{E}$ façade of the experimental rammed earth wall was divided into four panels with $160^{\mathrm{x}} 45\left(\mathrm{~cm}^{2}\right)$. The reference mortars CL2 and CL3, and mortars with the best workability among the ones with earth for lime/finer sand substitution, CL2_25e and CL3_10e, were prepared again but with an electric mixer blade. A first irregular layer of each mortar with higher water/(lime+earth) ratio was applied on the $\mathrm{E}$ façade of the wall, after rainy days (the wall was already humid), and let to dry for two days; another layer with water/(lime+earth) ratio of Table 3 was applied over the previous; the render had a total thickness of $2 \mathrm{~cm}$. The mortars were not sprayed with water because the weather was humid. No visual shrinkage occurred on the renders. Considering the weight proportions of Table 3 , the rendering panels of Figure 4 have weight proportions of, from left to right, 1:0:7.7, 1:0.3:10.3, 1:0.4:11.2 and 1:0:11.6 of air lime:earth:sand.

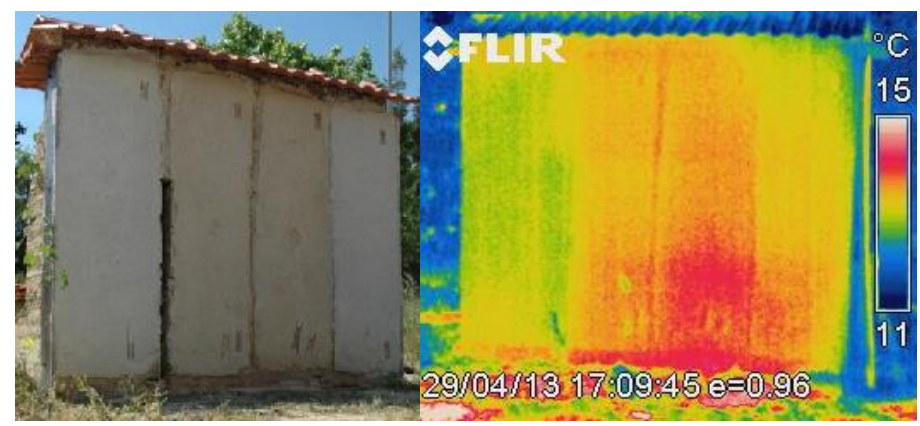

Figure 4. From left to right, renderings CL2, CL2_25e, CL2_10e and CL3 on rammed earth wall and thermography image after spring sunny days.

At the age of 90 days the renderings were characterized in terms of superficial hardness by pendular sclerometer and by shore A durometer, ultrawave velocity and water absorption under low pressure by Karsten tubes. A thermography image of the E façade after spring sunny days is presented in Figure 4. It can be seen that, even after some dry days, there is some rising capillary from the ground and that the panels with earth behave differently in terms of temperature, due to different hygroscopic performance.

\subsection{Results and discussion}

Table 4 presents the thermal conductivity of the rammed earth wall, with high moisture and after sunny days, of mortars on bricks and of prismatic mortar samples.

Table 4. Average and standard deviation of thermal conductivity of rammed earth wall after rain and in drier conditions, of mortars on bricks and of prismatic mortar samples.

\begin{tabular}{lll}
\hline Samples & & $\lambda$ \\
& & {$[\mathrm{W} /(\mathrm{m} . \mathrm{K})]$} \\
\hline Unrendered RE & After rain & $1.23 \pm 0.36$ \\
& Drier Cond. & $0.67 \pm 0.17$ \\
\hline Mortar on brick & CL2 & $0.43 \pm 0.06$ \\
& CL2_25e & $0.52 \pm 0.09$ \\
& CL3_10e & $0.58 \pm 0.15$ \\
& CL3 & $0.50 \pm 0.06$ \\
\hline Mortar prism. & CL2 & $0.74 \pm 0.01$ \\
Samples & CL2_25e & $0.73 \pm 0.01$ \\
& CL3_10e & $0.68 \pm 0.06$ \\
& CL3 & $0.77 \pm 0.03$ \\
\hline
\end{tabular}

It should be highlighted the remarkable difference on rammed earth wall thermal conductivity when the moisture conditions differ, varying between 0.67$1.23 \mathrm{~W} /(\mathrm{m} . \mathrm{K})$, but also the fact that even when the rammed earth is very humid, after a period of rain, $\lambda$ is still very good, particularly when compared, for instance, with a concrete dry wall (with values around 2.00W/(m.K) (Pina Santos \& Matias 2007).

At $65 \%$ RH mortar samples reflect a tendency of a slight decrease when earth is added while, when the mortars are applied and tested on bricks, the tendency seems to be inverse. However, the registered $\lambda$ values are remarkably good, and better for the mortars on brick than for the mortars itself (tested on prismatic samples), respectively with average values of $0.55 \mathrm{~W} /(\mathrm{m} . \mathrm{K})$ and $0.70(\mathrm{~W} /(\mathrm{m} . \mathrm{K})$ when earth is added.

Table 5 presents the superficial hardness of the unrendered rammed earth wall and of the panels with the different mortar renderings determined by pendular sclerometer and also of mortars applied on bricks determined by durometer. The sclerometer could not be applied on the samples of brick because the impact caused the detachment the mortar layer. Regarding the superficial hardness by sclerometer, the mortar renderings of the rammed earth wall present lower superficial resistance than the wall itself, 
as it should be in order to really protect the wall; otherwise they would induce tensions on that wall. A tendency to an increase of mortar superficial hardness can be pointed out when the earth is added and renderings with 1:3 volumetric proportion present higher values than those with 1:2 proportion.

Using the durometer to evaluate the superficial hardness it can be mentioned that all the samples present lower hardness than the wall itself, what induces compatibility between them. The renders with $25 \%$ earth applied on the wall present a good hardness, almost similar to the wall, while all the other show values of the same order. There is no correspondence between the hardness of renders on the wall and mortars applied on bricks and between the tendency obtained with the durometer and the one observed with the sclerometer.

Table 5. Average and standard deviation of superficial hardness of unrendered rammed earth, of rammed earth renderings and of mortars on bricks by pendular sclerometer and by durometer.

\begin{tabular}{llcl}
\hline Samples & & $\begin{array}{c}\text { Sclerometer } \\
\text { [Vicker] }\end{array}$ & $\begin{array}{l}\text { Durometer } \\
\text { [Shore A] }\end{array}$ \\
\hline Unrendered RE & & $87 \pm 6$ & $71.5 \pm 11.8$ \\
\hline RE renders & CL2 & $79 \pm 4$ & $62.8 \pm 7.8$ \\
& CL2_25e & $80 \pm 4$ & $70.0 \pm 20.5$ \\
& CL3_10e & $84 \pm 6$ & $63.8 \pm 7.0$ \\
& CL3 & $83 \pm 5$ & $64.8 \pm 9.9$ \\
\hline Mortar on brick & CL2 & & $65.7 \pm 9.2$ \\
& CL2_25e & & $62.9 \pm 11.7$ \\
& CL3_10e & $67.4 \pm 7.8$ \\
& CL3 & & $60.8 \pm 9.0$ \\
\hline
\end{tabular}

Table 6 presents the velocity obtained by ultrawave on the unrendered rammed earth wall, on renderings applied on the wall and on mortars on bricks. It presents also the water absorbed under low pressure by Karsten tubes after 5 minutes by the same samples and by the uncoated brick.

Table 6. Average and standard deviation of velocity by ultrawave and of water absorbed by Karsten tubes by unrendered rammed earth, by rammed earth renders, by uncoated bricks and by mortars on bricks.

\begin{tabular}{llll}
\hline Samples & & $\begin{array}{c}\text { UW veloc. } \\
{[\mathrm{m} / \mathrm{s}]}\end{array}$ & $\begin{array}{c}\text { WA 5min } \\
{[\mathrm{ml}]}\end{array}$ \\
\hline Unrendered RE & & $928 \pm 112$ & $14.8 \pm 0.8$ \\
\hline RE renders & CL2 & $551 \pm 94$ & 11.4 \\
& CL2_25e & $775 \pm 98$ & 17.9 \\
& CL3_10e & $725 \pm 104$ & 5.1 \\
& CL3 & $740 \pm 172$ & 8.2 \\
\hline Uncoated bricks & & & $0.4 \pm 0.2$ \\
\hline Mortar on brick & CL2 & $936 \pm 109$ & 0.8 \\
& CL2_25e & $918 \pm 361$ & 4.4 \\
& CL3_10e & $942 \pm 362$ & $4.9 \pm 1.5$ \\
& CL3 & $1016 \pm 174$ & $9.3 \pm 2.7$ \\
\hline
\end{tabular}

A higher ultrawave velocity reflects a denser material, without significant cracks. Once again renders on the wall present lower values compared to the wall itself, what may induce a compatible microstructure. The render with $25 \%$ earth applied on the wall present the highest UW velocity, higher than the reference mortar render CL2 and similar to mortars with $1: 3$ volumetric proportion. The same tendency is not obtained with mortars on bricks, where almost all mortars show similar values and only CL3 present a higher result.

The water absorption test with Karsten tubes presented a lot of difficulties, mainly because of detachment of the tubes during the 5 minutes of test. Some of the results are only the average of two samples and that is the reason why standard deviation is not always registered. It should be highlighted the very low absorption of the uncoated bricks and of mortar CL2 applied on bricks. Regarding renders one should bear in mind that they should be a first barrier protecting the wall from rainy water, while not being a vapour barrier, in order to allow the water vapour to be eliminated from the wall. It can be noticed that the best behaviour of renders on the wall is presented by the render with $10 \%$ earth and that only the render with $25 \%$ earth absorb more water than the unrendered wall. In terms of the mortars on bricks and maybe due to the reduced water absorption of the brick itself, the tendency is completely different, being CL2 mortar the one with the best behaviour, while mortar CL3 present the worst behaviour. In face of the results obtained particularly with this test, it seems that the support on what the mortars and rendering systems are applied changes the microstructure of the mortars itself and, thus, its characteristics.

\section{CONCLUSIONS}

The study that is presented in this paper, and that still is going on, intended to, systematically, evaluate the characteristics of air lime mortars and air limeclayish earth mortars, and compare it with the characteristics of rammed earth walls. An initial part of work was to define the best experimental procedures to evaluate those characteristics by non-destructive methods that can be applied on existent walls. Some difficulties arise, like problems of adherence of vertical Karsten tubes on rammed earth or who to evaluate $\lambda$ of renderings on walls, but were overcome. Different supports, like the case of ceramic hollowed brick or mortar samples without the effect of a support, can lead to different results and, for that reason, an effort should be made to characterise more widely rammed earth walls and their renderings.

As evidenced by many vernacular architecture examples and by the results of this paper, air lime and air lime-clayish earth mortars seem to behave 
properly as renders of rammed earth wall, even with problems of capillary rise. The mechanical and physical characterization showed the compatibility of lime and lime-earth mortars with the wall (a guarantee of not leading to their degradation, not assured by many other kinds of rendering mortars), and contributing for its effective protection, namely in face of rainy water degradation. Furthermore, it could be validated by tests that earth as a building material for mortars confer them particular good workability characteristic, while reducing its embodied energy.

A deeper knowledge on rammed earth vernacular walls and on traditional renderings will allow correct and well-founded interventions on existent earthen heritage, as well as good building practices for new earthen buildings.

\section{ACKNOWLEDGEMENTS}

Authors are grateful to the Portuguese Foundation for Science and Technology for supporting projects PTDC/ECM/100234/2008 and EXPL/ECMCOM/0928/2012. Acknowledgments are also due to Centro da Terra Association by the possibility of testing the experimental wall, to companies Lusical and Sorgila by providing the air lime and the clayish earth.

\section{REFERENCES}

Andrejkovicová, S., Velosa, A., Rocha, F. 2013. Air limemetakaolin-sepiolite mortars for earth based walls. Construction Building Materials 44: 133-141.

Arizzi, A., Viles, H., Cultrone, G. 2012. Experimental testing of the durability of lime-based mortars used for rendering historic buildings. Construction and Building Materials 28: 807-818.

Azeredo, G., Morel, J. \& Lamarque, C. 2008. Applicability of rheometers to characterizing earth mortar behaviour. Part I: Experimental device and validation. Materials \& Structures 41: 1465-1472.

Bruno, P., Faria, P., Candeias, A. \& Mirão, J. 2010. Earth mortars use on pre-historic habitat structures in south Portugal. Case studies. Iberian Archaeology 13: 51-67.

Bui, Q., Morel, J-C. 2009. Assessing the anisotropy of rammed earth. Construction and Building Materials 23 (9): 30053011.

Coroado, J., Paiva, H., Velosa, A. \& Ferreira, V. 2010. Characterization of renders, joint mortars and adobes from traditional constructions in Aveiro (Portugal). Architectural Heritage 4: 102-114.

Faria, P., Silva, V., Pereira, C., Rocha, M. 2012. The monitoring of rammed earth experimental walls and characterization of rammed earth samples. In Mileto, Vegas \& Cristini (eds.), RESTAPIA 2012 - Int. Conf. on Rammed Earth Conservation, Rammed Earth Conservation: 91-97. London: Taylor \& Francis.
Faria, P., Tavares, M., Menezes, M., Veiga, R., Margalha, G. 2010. Traditional Portuguese techniques for application and maintenance of historic renders. In J.Walek, C.Groot \& J.Hughes (eds), RILEM Proceedings Pro 078: 609-617. Prague: RILEM.

Faria, P., Henriques, F. \& Rato, V. 2008. Comparative evaluation of lime mortars for architectural conservation. Cultural Heritage 9: 338-346.

Faria-Rodrigues, P. 2005. Rendering of raw earth walls. In M. Fernandes \& M. Correia (eds), Earth Architecture in Portugal: 68-73. Lisbon, Argumentum.

Fernandes, M., Mirão J., Velosa, A., Candeias, A. 2012. Estabilización de tierra com cal. Ventajas y desventajas. Terra 2012 (CD). Lima: PUCPeru.

Fragata, A., Veiga, R. (2010). Air lime mortars: the influence of calcareous aggregate and filler addition. Materials Sc. Forum 636-637: 1280-1285.

Gomes, I. \& Faria, P. 2011. Repair mortars for rammed earth constructions. In V.P Freitas, H.Corvacho \& M.Lacasse (eds), Proceedings of the XII DBMC - 12th Int. Conf. on Durability of Building Materials and Components, Vol.2: 689-696. Porto: FEUP.

Gomes, I., Gonçalves, T. \& Faria, P. 2012a. Earth-based repair mortars: experimental analysis with different binders and natural fibers. In Mileto, Vegas \& Cristini (eds.), RESTAPIA 2012 - Int. Conf. on Rammed Earth Conservation, Rammed Earth Conservation: 661-668. London: Taylor \& Francis.

Gomes, I., Gonçalves, T. \& Faria, P. 2012b. Unstabilised rammed earth: characterization of material collected from old constructions in south Portugal and comparison to normative requirements. Architectural Heritage (on line, doi/abs/10.1080/15583058.2012.683133).

Hall, M. \& Djerbib, Y. 2004. Rammed earth sample production: context, recommendations and consistency. Construction and Building Materials 18 (4): 281-286.

Lima, J. 2013. The contribution of clay plaster to a healthy indoor environment: the case study of the Southwest Algarve clays (in Portuguese). In 2nd CIHEL - Int. Conf. Housing on Portuguese Speaking Countries (CD). Lisbon: LNEC.

Margalha, G., Veiga, R., Santos-Silva, A. \& Brito, J. 2011. Traditional methods of mortar preparation: the hot lime mix method. Cement and Concrete Composites 33: 796-804.

Minke, G. 2011. Shrinkage, abrasion, erosion and sorption of clay plasters. Informes de la Construcción 63 (523): 153158.

Pina dos Santos. C., Matias, L. 2007. U-values of building envelope elements (in Portuguese), ITE 50. Lisbon: LNEC.

Pkla, A., Mesbah, A., Rigasse, V. \& Morel, J. 2003. Compairaison de méthodes d'essais de mesures des characteristiques mécaniques des mortiers de terre. Matériaux et Constructions 26: 108-117.

Stazi, A. 2003. Ana experimental valuation of mud-plaster stabilized with natural materials in two Italian regions. In Terra 2003: 542-551. Iran: ICHO.

Veiga, R., Fragata, A., Velosa, A.; Magalhães, A., Margalha, G. 2010. Lime-based mortars: viability for use as substitution renders in historical buildings. Architectural Heritage 4: 177-195. 